\title{
Lived Experiences of End Stage Renal Disease Patients Undergoing Continuous Ambulatory Peritoneal Dialysis Therapy
}

\author{
M. Hanif Prasetya Adhi, Yanny Trisyani*, Etika Emaliyawati \\ Faculty of Nursing, Universitas Padjadjaran, Bandung, Indonesia \\ Corresponding Email: yanny.trisyani@unpad.ac.id
}

Received: 19-08-2020 Revised: 21-12-2020 Accepted: 21-12-2020

\begin{abstract}
End stage renal disease (ESRD) is a serious chronic disease that resulted from complications of chronic renal failure and a final diagnosis that requires treatment modalities such as dialysis or continuous ambulatory peritoneal dialysis (CAPD). However, CAPD is rarely selected as renal replacement therapy by ESRD patients in Indonesia. Therefore, the phenomenon associated with patients undergoing CAPD is unclear, especially in Indonesia. The purpose of this study was to explore the lived experiences of ESRD patients undergoing CAPD therapy. The research method employed qualitative descriptive phenomenology. The participants in this study were 10 ESRD patients with CAPD. Data collection utilized semi-structured interviewed and data was analyzed using the Colaizzi approach. The result of the study was explained through 6 themes. These are: 1) Condition improved with CAPD, 2) Freedom of activity, 3) Between feeling better and bored 4) Health is increased, 5) It is sustained life, 6) Resignation to accept illness. In conclusion, the patients with CAPD felt significant positive changes in their life and CAPD is considered life-sustaining for the participants, as the majority of the symptoms was decreased significantly. Therefore, the partisipants felt their conditions improved better. The unpleasant sides of CAPD are feeling bored. The support of the family is important as it produced strength and passion for patients in undergoing CAPD.
\end{abstract}

Keywords: Continuous ambulatory peritoneal dialysis, end stage renal disease, lived experience. 


\section{Introduction}

End stage renal disease (ESRD) is a serious complication of chronic renal failure and requires renal replacement therapy in the form of hemodialysis (HD), peritoneal dialysis (PD) or transplantation as mainstay treatments (Tannor, Archer, Kapembwa, Van Schalkwyk, \& Davids, 2017). ESRD patients condition could be worsening which can lead to an emergency conditions and required prompt treatment (Shari, Suryani, \& Emaliyawati, 2014). ESRD has been recognized globally as a complication of disease. In Taiwan, the prevalence of ESRD reached 2,584 per million in 2010, while around 2,260 and 1,870 were reported in Japan and the US (Chao et al., 2018). In Indonesia, the number of newly diagnosed ESRD or the ESRD incidence increased from 9649 in 2010 to 30831 in 2017 and the prevalence of ESRD sufferers increased from 11484 in 2010 to 77892 in 2017 (Abdurahman, Bandiara, \& Supriyadi, 2019). Basic Health Research (Riskesdas, 2013) report has indicated that the prevalence of ESRD in Indonesia is around $0.2 \%$, and this will continue to increase with the increasing number of elderly.

ESRD affects nearly every organ system in the body with a variety of signs and symptoms. The resulting physical and mental disabilities affect the patient in their daily life activities. Hemodialysis, peritoneal dialysis (PD) and kidney transplantation are modalities for renal replacement therapy. Hemodialysis is the most common mode of therapy for ESRD worldwide, in New Zealand and Australia, approximately 17.7 and $9.1 \%$ of patients (USRDS, 2012). Based on the Indonesian Renal Registry / IRR (2014), the majority of services provided at dialysis facilities are hemodialysis (82\%). The rest were in the form of CAPD services $(12.8 \%)$, transplantation $(2.6 \%)$ and CRRT $(2.3 \%)$.

There are some ESRD patients who died due to queues or long waiting lists for $\mathrm{HD}$ even though it was time to do dialysis, while the hospital has added HD machines, but until now there is still a waiting list for ESRD patients to have HD every week. This phenomenon is experienced by dialysis nurses, and the nurse educate HD patients to consider other renal replacement therapies such as CAPD to reduce the waiting list. However, CAPD is still minimally practiced in Indonesia due to several obstacles felt by patients. Nurses with advanced skills are required to be able to educate the patients regarding this intervention (Mulyana, Trisyani, \& Emaliyawati, 2020).

Althought, ESRD patients who undergo CAPD therapy may experience many benefits, such as freedom of lifestyle and being able to do activities just like healthy people. Maintaining a lifestyle perspective was previously considered important in maintaining a normal lifestyle. In addition, changing therapy modalities, moving from one modality to another is a common experience. Some patients report a worse experience using HD than PD (Morris, Liles, \& Roskell, 2015).

In this context, the results of preliminary studies have indicated that at the beginning of dyalisis therapy the patient, feel fear, shock, and refuse the theraphy. In addition, at the first time the patient did dialysis with CAPD, the patient felt stressed and unable to do anything. The patient feels anxious and worried about CAPD therapy, because he perceived that the CAPD therapy it is only to prolong his life and he perceived that the possibility of survival is about $50 \%$ and the possibility of passed away is also about $50 \%$ (interview Mr B). The experience of patients undergoing CAPD therapy is a unique experience. This phenomenon related to lived experienced of patients undergoing CAPD therapy cannot be described quantitatively because the meaning, perception, burden, or quality of life possessed by each patient is different and unique.

The research about lived experiences of ESRD patients who use CAPD therapy is still limited both in Indonesia and abroad, so researchers are interested in exploring patient experiences while undergoing CAPD in a hospital in West Java Province. Similar studies have often been carried out in Indonesia with the target or as informant being family members of patients with terminal renal failure who undergo hemodialysis (HD) therapy. Patients with terminal renal failure must perform renal replacement therapy by 
choosing appropriate therapy and becoming routine so that it affects their quality of life. The hope of recovering their health, only prolonging life or providing a better quality of life is a consideration of the chosen therapy. ESRD patients may need to switch to another kidney replacement therapy (Awuah et al., 2013). The result study of Yalamanchili et al. (2013) have indicated that patients feel that CAPD is beneficial, while others are worried about complications that can have serious consequences for their bodies. So that medical personnel also need to provide promotional steps starting before the patient initiates dialysis. So that the patient knows the context of each dialysis therapy he will choose. Therefore, to explore the values, meanings, burdens, benefits, feelings, and life experiences of these patients, it is through conducting research with qualitative phenomenological methods, to gain a deeper understanding of the lived experiences of people with ESRD who undergo CAPD therapy.

Therefore, one way to explore the values, meanings, burdens, benefits, feelings, and life experiences of patients is to conduct research with qualitative methods to obtain a more indepth and specific picture of the experiences of individuals with ESRD undergoing kidney replacement therapy using CAPD.

\section{Method}

This study employed a qualitative method with a descriptive phenomenology approach to explore the phenomenon. Descriptive phenomenology is the study of human experience it seeks to gain understanding of the human world as the basis of science which brings justice to the experience of everyday life and goes to the things themselves (Christensen, Welch, \& Barr, 2017).

The research participants was selected through purposive sampling technique, based on certain considerations made by the researcher or inclusion criteria as follows: Participants aged $\geq 18$ years, participants who suffer from end stage renal disease, active participants with CAPD therapy $\geq 1$ years, and able to communicate in Indonesian and cooperatively. The participants of this study were accessed through the Hemodialysis Unit of the Hospital in West Java by observing the list of ESRD patients who had CAPD therapy. The list which contained identity data and patient's phone numbers that could be contacted were also provided by the doctor in charge of CAPD theraphy. After finding participants who match the inclusion criteria, the information related to the study was provided to the participants. The inform consent then provided to the participants which consists of the research objectives and asksed the willingness to be a participant in this study. Once, approval has been obtained from participants to contribute in this study, the researcher discussed with the participants regarding willingness to be interviewed, the time and place for the interview to be conducted. In this study, 10 participants of ESRD patients who undergo CAPD were participated.

This research was conducted in February 2020 and Ethic approval for conducting this study was obtained from the Health Research Ethics Committee of the UNPAD Faculty of Medicine no. 216 / UN6.KEP / EC / 2020. Data collection in this study utilized semi-structured in-depth interviews. Data analysis was conducted through the Colaizzi approach for analysis as follows :1) Read all the transcript results repeatedly, 2) Look back at data transcripts and select statements that are significant, 3) Formulate the meaning or meaning of important statements, 4) Categorize these meanings into themes according to participants' expressions, 5) Form a description of the phenomenon, 6) Identifying the fundamental structure, 7) Confirming or re-validating the description of the phenomenon to the participants (Colaizzi, 1978).

\section{Results}

The phenomenon of lived experience of patients undergoing CAPD was described through 6 themes, namely: 1) Condition improved with CAPD, 2) Freedom of activity, 3 ) Between feeling better and bored 4) Health is increased, 5) It is sustained life, 6) Resignation to accept illness. These themes will be explained in the next section. 
Theme 1: Condition improved with CAPD

This theme was derived from the experiences of participants who revealed changes in the conditions felt by participants during CAPD that made participants felt that their conditions were getting better after switching therapy to CAPD. Participants felt a difference in their conditions, when he underwent HD therapy for more than a year and then Shifted to CAPD. They revealed that CAPD gave more benefits because they felt significant changes and they felt that the CAPD has made their body felt more comfortable, as indicated below:

So the benefits are a lot more, four times a day, this is not a problem, this is a routine, the same way when we pray, since at 5 o'clock in the morning I finished prayer, then I sometimes overslept..then my wife .. will help me to complet the CAPD therapy .. if I overslept.

It was revealed that their condition was getting better and better.

CAPD provides greater flexibility for patients in terms of time management: 1) Patients who are treated with CAPD, should be trained to adapt the CAPD prescription procedure in their daily activities if necessary and; 2) Clinical visits related to the implementation of CAPD are scheduled every $4-12$ weeks, compared to three times a week to HD unit for patients treated with HD.

After the patients shifted to CAPD for more than a year and the patiens felt, that several complaints such as hypertension, nausea, anorexia, all are felt decreasing. The patient feels that CAPD is suitable for renal failure treatment, as it made the patients feel more comfortable and healty. They perceived that it is because they felt several complaints had decreased, and there were even participants who mentioned that they had no more complaints after shifted to CAPD., as indicated above:

\section{Theme 2: Freedom of Activity}

They revealed that they could freely do light activities after undergoing CAPD. All participants have various types of mobility, such as being able to ride their own vehicle, doing small businesses, doing house chores, even light exercise. As Mrs. I below:

CAPD patients are very likely to do their job, so it has no impact on their

income financially and, they could travel more freely than HD patients (Makkar, Kumar, Mahajan, \& Khaira, 2015).

In this case, CAPD has increased autonomy and independence for the patients suffering from end-stage renal disease compared to HD facilities, and this is reflected in higher employment rates for patients treated with home CAPD compared to HD facilities (François \& Bargman, 2014). A similar experience was also expressed by $\mathrm{Mr}$. G as follows:

Participants felt that after switching to CAPD they became independent and independent of machine. As expressed by Mrs. I below:

\section{Theme 3: Between feeling better and bored}

This theme was taken from participants who said that CAPD was simpler, more practical, the distance and time for dialysis had no obstacles. As stated by Mr. E below:

The majority of patients with renal failure can be treated with PD, an effective dialysis modality with similar overall survival at a lower cost compared to HD (François \& Bargman, 2014). A similar experience was also expressed by Mr. A, who stated that during the CAPD there were no perceived obstacles related to the cost.

The ease of information was also revealed by Mrs. I which stated that the information of CAPD was obtained from nurses. However, all participants expressed the ease of CAPD information can be accessed anywhere such as from the internet, books, or people who are undergoing CAPD, so it is easier to get information.

During conducting CAPD there are also some limitations, including preparing CAPD fluids, confusion of CAPD equipment, blockage of the tube, body shivering after changing the fluids, and others. New patients with ESRD may be more eager to change their life habits to meet dialysis care requirements. But over time, patients feel bored and easily frustrated with the need to adhere to a long list of dietary restrictions and CAPD fluid replacement (Chan, Zalilah, $\&$ Hii, 2012). The following is an expression from participant no. 1, P2, P3, and P5, which revealed that they were saturated with CAPD 
fluid replacement routines had to be prepared in advance, as conveyed by Mr.A, below:

\section{Theme 4: Health is Increases}

This experience was expressed by participants when undergoing CAPD felt that their health had improved such as improved blood pressure, condition became more fit, improved physical condition, body became more energetic and so on. Below is an expression from Mrs. I who stated that her physical condition was improving.

They also felt changes in their psychosocial aspects such as a good sleep patterns, opening up to the environment, feeling ashamed was gone, and not experiencing stress. CAPD treatment offers increased autonomy and control, flexibility in daily life and less social restrictions can also be reasons for better psychological health in patients (Makkar et al., 2015). CAPD patients also showed a greater reduction in depressive symptoms and greater patient satisfaction with treatment, because having depressive symptoms had a greater effect on HRQOL than the CAPD modality itself and the prevalence of depressive symptoms remained high despite the tendency to increase over time (Jung et al., 2016). As indicated in the quotation below:

In addition, they felt that their life was back to normal like before suffering from ESRD. Some participants revealed that they seemed to return to their former identity. Most CAPD patients could easily carry out routine activities such as working, walking up the stairs, washing, driving, traveling and also do not have sexual problems. CAPD patients were more energetic, cheerful, and active and have a good level of well-being. They become more flexible, such as returning to themselves before being sick (Paraskevi, 2011), as indicated below:

\section{Theme 5: CAPD sustained life}

Waiting for the end, as part of the experience of going through the day, is a sad approach to life. Trapped in a process without end and life like being robbed because dialysis is only their only hope at this time. Although, dialysis keeps patients alive, and death is inevitable for all humans, CAPD is like the last call of life for them (Lin, Han, \& Pan, 2015). The same experience was expressed by Mr. $\mathrm{N}$ as seen in the quote below:

Patients perceived that they live one day more anticipating their death and hoping to die with dignity, i.e. death without suffering (Lin et al., 2015). A similar experience was also expressed by Mrs. L who was worried about lifetime dialysis because there are relatives who had the same history and eventually died. Patients experienced uncertainty with a lack of information and unexpected illnesses, between life and death, and difficulty planning their life ahead. They were worried how long they will live with this disease. Patients also fear they will live alone, and believe that it will end in death (Sahaf \& Ilali, 2017).

\section{Theme 6: Resignation to accept the disease}

This experience was expressed by several participants who experienced ESRD and inevitably faced therapy that the participants had previously not known about the therapy. As expressed by Mr. T :

Positive meaning of a disease has implications for the emergence of a feeling of resignation to the patients. When sickness is interpreted positively by the patient, such as being patient and optimistic, the immunity in the body can increase. This affects their behavior (actions) both towards themselves and others which are related to health, illness, disease and medication. The pain felt by the patient is considered a disease that has become the destiny of Allah SWT. This statement assumed that pain must be accepted sincerely by the patient. Finally, the patient was resigned and patient with pain. This was because illness is considered as a test from Allah SWT with the aim that the sufferer would be better. On the other hand, illness can lead to an upbeat and optimistic attitude in the sufferer when sick, so that the patient has hope for recovery (Rahmawati \& Muljohardjono, 2016). As expressed by Mrs. I, as follows:

When a person is afflicted with illness, spiritual power can aid in healing. The strength of one's spirituality can be an important factor in how to deal with changes caused by chronic disease (Potter \& Perry, 2005). 


\section{Discussion}

Participants expressed that at the begining of the CAPD therapy, their body needed adaptation about five to six months. They revealed that their initial complaints such as swelling, weakness, anorexia, nausea, shortness of breath etc. gradually decreased. Another experience, there were also some participants who felt afraid because they will feel similar complaints with the previous therapy, before CAPD. Eventually, in a period of about five to six months, such complaints had decreased and even most of the complaints has been felt disappeared by certain participants.

According to Ören and Enç (2013) changes in conditions for the better outcomes are considered an important indicator of the results of treatment provided to participants. With CAPD they felt there was there was changes in their condition and they felt the benefits of CAPD and therefore the participants believed that CAPD is more safe. This was reflected as a feeling of satisfy, comfort, and feeling the benefits of CAPD for their condition because in the previous therapy they did not feel it. They perceived that CAPD is more suitable for them as an ESRD patients as also it less painful compared to the previous therapy which often causes participants to undergo frequent intravenous line insertion. This was explained by (Alharbi, Alraddadi, Alharbi, \& Alharbi, 2017) that ESRD patients require dialysis almost every day, which inevitably affects their symptoms and emotions, for example, muscle weakness is the most frequent and, medication-related symptom among patients with ESRD may experience more intense emotional distress due to treatment-related symptoms than patients with other illnesses.

Participants who had undergone CAPD independently for more than a year indicated that they were able to mobilize, to do their homework, and socialize with local community members. CAPD allows individuals to independently adjust their lifestyle (Airheart, 2016). In addition, CAPD therapy achieves and maintains normality by maximizing the flexibility, freedom and mobility that is possible with CAPD. Ekelund and Andersson (2010) expressed their experience that CAPD can be seen as an easier option. Patient experience reveals that CAPD offers positive lifestyle choices, for example the patient is free during the day and the patient does not need to go to a dialysis unit, is a simpler option compared to HD. That is because they can set their own time about their treatment so they are able to schedule their activities without worrying about going to the hospital which takes time and money. They find it simpler and more practical than having to go to a dialysis center every week.

Patients undergoing CAPD fluid replacement have to spend a lot of time each day either outdoors or indoors. It is important for the patient to be able to find a way to spend the time, so that the patient does not get bored easily. According to Charles Corr (2015) CAPD patients experience a feeling of saturation saturation because they have to change fluids up to four times a day, to avoid saturation some patients can watch TV and play video games to avoid boredom, or others prefer to read and chat with other people. Some patients listen to music, sleep while assisted by someone closest to replace fluids. When replacing CAPD fluids, this can be a good opportunity to spend time in a way the patient can enjoy.

Patients who routinely do CAPD feel that their health has improved or improved after undergo CAPD within a period of five to six months as a period of adaptation. After six months, several participants revealed that their physical health were better, which were described by normal blood pressure, no shortness of breath, no swelling, no weakness, ideal body weight, and more powerful body. Research conducted by Ghaffar, Chasani, and Saktini (2017)

also revealed similar results. This can be linked to the elimination of azotemia toxin in ESRD patients through the implementation of CAPD that is conducted continuously every day and every six hours or four times a day of CAPD treatment whereas in HD treatment it is fluctuating because dyalisis procedure only condnucted for two to three times a week in the hospital. Azotemia toxin elimination is closely related to the severity of symptoms experienced by the patient.

The psychosocial factors are also improved 
in the participants after undergoing CAPD. This shows that improved physical health, psychological well-being and satisfaction with CAPD has led to the improvement treatment adherence and better disease management. This positive result may be directly related to the increase in HRQOL.

The participants expressed that CAPD was only intended to prolong or maintain the condition of their body so that their life would be longer because they were assisted by CAPD. Participants realized that the ESRD disease could not be cured and participants could only survive with CAPD. Lin et al. (2015) revealed that ESRD patients are trapped in an endless process with dialysis. ESRD patients are always exposed to continuous dialysis treatment unless they have a successful kidney transplant. Day after day they live waiting to end and hope to die well.

CAPD is like the last call of life for them. As a result, the participants found that they wanted to value life more by anticipating their own death and making hopes for a meaningful death, that is death without suffering. They did this because they expressed their concern of having dialysis all their life. Many ESRD patients though they were undergoing CAPD had severe symptoms for the participants, indicating that palliative care should be an integral part of nursing services (Hwang, Tsai, \& Chen, 2010).

The thing that was most feared by the participants was death, as well as their families who were not ready to lose their loved ones. However, what worries the participants even more was that if the participant falls in a helpless condition, it can be troublesome for their family, but participants can only accept and resign everything to medical personnel no matter what. The commonness of patients often makes communication between medical personnel and patients felt hampered. This could affect the patient's attitude that they felt, they are only able to resign and accept medical intervention based on their illness.

In this study, each participant interpreted ESRD differently, ESRD as a test, as a remedy for sins, as a warning and so on. According to Ulrich (2008), the grieving response has entered a period of acceptance if the person has accepted the conditions and consequences he or she has experienced. The belief in God's power made the participants in this study felt resigned, sincere, and accepted the destiny given by God. Hope has a close relationship with spiritual matters. If there are obstacles in the spiritual, it can cause individuals to have low expectations and lead to despair.

Getting closer to God through selfreflection is what most participants feel is important in their spiritual life. Self reflection has encouraged participants to strengthen their knowledge of religion and improve the quality of prayer in their everyday life.

\section{Conclusion}

The phenomenon of the lived experience of ESRD patients undergoing CAPD therapy is explain through the 6 themes obtained from this study, namely: Condition improved with CAPD, Freedom of activity, Between feeling better and bored, Health is increased, CAPD making life sustained and, Resignation to accept the disease. The researchers concluded that patients receiving CAPD treatment have various kinds of positive sides. Participants experienced significant positive changes in their life. Therefore, CAPD is considered life-sustaining for the participants. After undergoing CAPD participants are able to do several important activities that were not able to do when they were in previous treatment. With CAPD most of participants the symptoms such as swollen feet, shortness of breath, inability to move were decreased. So that the partisipants felt that their conditions improved better, therefore the participants considered to continue the CAPD treatment. The unpleasant sides of CAPD is feeling bored because of frequent practices fluid replacement in a day, yet there are many ways that can be done by participants to avoid boredom. Furthermore, the support provided by the family and the willingness to be healthier, has produced strength and passion for ESRD patients in undergoing CAPD.

\section{References}

Abdurahman, A., Bandiara, R., \& Supriyadi, R. (2019). Mon-055 The Growing Burden 
Of End Stage Renal Disease In Indonesia: Ten Years of The Indonesian Renal Registry Reports. Kidney International Reports, 4(7). https://doi.org/10.1016/j.ekir.2019.05.843

Airheart, J. W. (2016). Lived Experiences of Individuals with End-Stage Renal Disease on Peritoneal Dialysis. Retrieved March 4, 2020, from https://digitalcommons.gardnerwebb.edu/nursing_etd/ 253

Alharbi, A. A., Alraddadi, R. M., Alharbi, A. A., \& Alharbi, Y. A. (2017). Comparison of Saudi Arabian hemodialysis and peritoneal dialysis patients' illness perceptions. Renal Failure, 39(1), 187-192. https://doi.org/10.1 080/0886022x.2016.1256314

Awuah, K. T., Afolalu, B. A., Hussein, U. T., Raducu, R. R., Bekui, A. M., \& Finkelstein, F. O. (2013). Time to recovery after a hemodialysis session: Impact of selected variables. Clinical Kidney Journal, 6(6), 595-598. https://doi.org/10.1093/ckj/sft120

Chan, Y. M., Zalilah, M. S., \& Hii, S. Z. (2012). Determinants of compliance behaviours among patients undergoing hemodialysis in Malaysia. PloS One, 7(8), e41362. https:// doi.org/10.1371/journal.pone.0041362

Chao, J.-Y., Chien, H.-C., Kuo, T.-H., Chang, Y.-T., Li, C.-Y., Wang, M.-C., \& Yang, Y.H. K. (2018). Assessing the effect of oral activated vitamin $\mathrm{D}$ on overall survival in hemodialysis patients: a landmark analysis. BMC Nephrology, 19(1), 1-11. https://doi. org/10.1186/s12882-018-1111-2

Charles Corr. (2015). A "New Normal": life on dialysis-the first 90 days. National Kidney Foundation, Inc.

Christensen, M., Welch, A., \& Barr, J. (2017). Husserlian descriptive phenomenology: A review of intentionality, reduction and the natural attitude. Journal of Nursing Education and Practice, 7(8), 113-118. https://doi. org/10.5430/JNEP.V7N8P113

Colaizzi, P.F. (1978) Psychological research as a phenomenologist views it. In: Valle, R.S. and King, M., Eds., Existential-
Phenomenological Alternatives for Psychology, Oxford University Press.

Ekelund, M.-L., \& Andersson, S. I. (2010). "I need to lead my own life in any case"-a study of patients in dialysis with or without a partner. Patient Education and Counseling, 81(1), 30-36. http://dx.doi.org/10.1016/j. pec. 2009.10 .025

François, K., \& Bargman, J. M. (2014). Evaluating the benefits of home-based peritoneal dialysis. International Journal of Nephrology and Renovascular Disease, 7, 447. https://dx.doi.org/10.2147\%2FIJNRD. S50527

Ghaffar, M. R. A., Chasani, S., \& Saktini, F. (2017). Perbandingan Kualitas Hidup Pasien Penyakit Ginjal Kronik yang Diterapi dengan Continuous Ambulatory Peritoneal Dialysis Atau Hemodialisis (Comparison the Quality of Life of Patients with Chronic Kidney Disease Treated with Continuous Ambulatory Peritoneal Dialysis or Hemodialysis). Diponegoro Medical Journal (Jurnal Kedokteran Diponegoro), 6(4), 1518-1528.

Hwang, S. J., Tsai, J. C., \& Chen, H. C. (2010). Epidemiology, impact and preventive care of chronic kidney disease in Taiwan. Nephrology, 15, 3-9. https://doi.org/10.1111/ j.1440-1797.2010.01304.x

Jung, H.-Y., Jang, H. M., Kim, Y. W., Cho, S., Kim, H.-Y., Kim, S.-H., . . Jo, S. K. (2016). Depressive symptoms, patient satisfaction, and quality of life over time in automated and continuous ambulatory peritoneal dialysis patients: a prospective multicenter propensitymatched study. Medicine, 95(21). https://doi. org/10.1097/md.0000000000003795

Lin, C.-C., Han, C.-Y., \& Pan, I.-J. (2015). A qualitative approach of psychosocial adaptation process in patients undergoing long-term hemodialysis. Asian Nursing Research, 9(1), 35-41. https://doi. org/10.1016/j.anr.2014.10.007

Makkar, V., Kumar, M., Mahajan, R., \& Khaira, N. (2015). Comparison of outcomes and quality of life between hemodialysis 
and peritoneal dialysis patients in Indian ESRD population. Journal of Clinical and Diagnostic Research: JCDR, 9(3), OC28. https://dx.doi.org/10.7860\%2FJCDR\%2F20 15\%2F11472.5709

Morris, A., Liles, C., \& Roskell, C. (2015). Exploring the challenges of living with peritoneal dialysis. Journal of Renal Nursing, 7(4), 175-178. http://dx.doi.org/10.12968/ jorn.2015.7.4.175

Mulyana, Y., Trisyani, Y., \& Emaliyawati, E. (2020). Relationship between healthcare provider's perception about patient safety and patient safety implementation in the emergency department. Jurnal Keperawatan Padjadjaran, 8(1). https://doi.org/10.24198/ jkp.v8i1.995

Ören, B., \& Enç, N. (2013). Quality of life in chronic haemodialysis and peritoneal dialysis patients in $\mathrm{T}$ urkey and related factors. International Journal of Nursing Practice, 19(6), 547-556. http://dx.doi.org/10.1111/ ijn.12098

Paraskevi, T. (2011). The role of sociodemographic factors in health-related quality of life of patients with end--stage renal disease. International Journal of Caring Sciences, 4(1).

Potter, P. A., \& Perry, A. (2005). Fundamental of Nursing, Concept, Process and Practice. Mosby Company.

Rahmawati, P., \& Muljohardjono, H. (2016). Meaning Of Illness Tinjauan Komunikasi Kesehatan Dalam Perspektif Islam (Meaning Of Illness in a Health Communication Review in an Islamic Perspective). Jurnal Komunikasi Islam, 6(2), 105-117. https://doi. org/10.15642/jki.2016.6.2.105-117
Riskesdas. (2013). Riskesdas 2013. Kementerian Kesehatan RI. Retrieved March 18, 2020, from https://pusdatin.kemkes. go.id/resources/download/general/Hasil\%20 Riskesdas\%202013.pdf

Sahaf, R., \& Ilali, E. S. (2017). Uncertainty, the overbearing lived experience of the elderly people undergoing Hemodialysis: a qualitative study. International Journal of Community Based Nursing and Midwifery, 5(1), 13.

Shari, W. W., Suryani, S., \& Emaliyawati, E. (2014). Emotional Freedom Techniques dan Tingkat Kecemasan Pasien yang akan Menjalani Percutaneous Coronary Intervention (Emotional Freedom Techniques and the level of anxiety of patients who will have percutaneous coronary intervention). Jurnal Keperawatan Padjadjaran, 2(3). https://doi.org/10.24198/jkp.v2i3.83

Tannor, E. K., Archer, E., Kapembwa, K., Van Schalkwyk, S. C., \& Davids, M. R. (2017). Quality of life in patients on chronic dialysis in South Africa: a comparative mixed methods study. BMC Nephrology, 18(1), 4. Retrieved from https://doi.org/10.1186/ s12882-016-0425-1

Ulrich, S. (2008). Cancer and Grief. Retrieved January 29, 2020, from https:// www.amazines.com

Yalamanchili, H. B., Murray, P., Awuah, K. T., Harden, P., Finkelstein, S. H., \& Finkelstein, F. O. (2013). The experience of dialysis therapy among younger adults. Paper presented at the Advances in peritoneal dialysis. Conference on Peritoneal Dialysis. 